\title{
Analysis of the Association between Eating Behaviors and Weight Loss after Laparoscopic Sleeve Gastrectomy
}

\author{
Ilana Nikiforova ${ }^{a}$ Royi Barneab Shir Azulaib Sergio Susmallianc, d \\ ${ }^{a}$ Department of Nutrition, Assuta Medical Center, Tel Aviv, Israel; ${ }^{b}$ Assuta Health Services \\ Research Institute, Assuta Medical Center, Tel Aviv, Israel; ' ${ }^{\circ}$ Department of Surgery, Assuta \\ Medical Center, Tel Aviv, Israel; d Faculty of Health Sciences, Ben-Gurion University of the \\ Negev, Beersheba, Israel
}

\section{Keywords}

Bariatric surgery - Eating behavior - Weight loss - Body mass index - Binge eating disorders

\begin{abstract}
Setting: In a private medical center, 300 patients who underwent a laparoscopic sleeve gastrectomy (LSG) were classified into 4 groups according to their eating behaviors (EB) preoperatively. During a 3-year postoperative follow-up, dietary changes in relation to weight loss were studied. Objectives: To explore the influence of abnormal EB on the outcome of sleeve gastrectomy. Background: Patients with morbid obesity often suffer from abnormal EB. After LSG, the outcome depends largely on improvement of the feeding behaviors acquired. Methods: This prospective study includes 300 patients who underwent LSG from 2013 to 2014, divided into the following 4 groups: binge eaters, snack eaters, sweet eaters, and volume eaters. Results: The average age was 41.65 years, the ratio of male to females was 1 to 2 . The average baseline body mass index (BMI) was 42.02. After 3 years, no significant change was found in the number of binge eaters $(p=0.396)$, but there was an $8.9 \%$ increase in snack eaters $(p<$ $0.001)$, a $12.9 \%$ increase in sweet eaters $(p<0.001)$, and $17.2 \%$ increase in healthy eating habits $(p<0.001)$. Sixty-five $(24.8 \%)$ patients did not experience changes in their eating patterns. However, after surgery, $24.6 \%$ of the patients continued with the same EB and 125 (49.5\%) patients changed from one EB to another unhealthy EB. Weight loss, measure as $\triangle B M I$, was similar in each group after 3 years, with a mean BMI of 29.8. When eating habits were related to different features such as gender, sports practice, type of work, smoking, marital status,
\end{abstract}


comorbidities, no influence on the operative results were found. Conclusion: LSG promotes the reduction of overeaters; however, it promotes a switch between other unhealthy EB. The significant increase in snack eaters and sweet eaters is outstanding, although it did not affect weight loss in the midterm follow-up. Worsening of eating habits after LSG is a common fact.

(C) 2019 The Author(s)

Published by S. Karger AG, Basel

\section{Introduction}

Obesity in Western countries is a health issue of epidemic proportions with no signs of abating and its incidence is also rising in low- and middle-income countries [1]. Countries with high economic resources are moderately successful in fighting the health consequences of being overweight, such as diabetes, hypertension, and hypercholesterolemia [2]. There is also an increased prevalence of overweight and obesity among children and adolescents due to an increased dietary intake and physical inactivity $[3,4]$.

Conservative treatments, either through drugs or through lifestyle modifications, do not provide satisfactory results in terms of weight loss over time and morbidity reduction in patients with severe obesity [5]. Compared to nonsurgical treatment of obesity, bariatric surgery leads to a greater body weight loss and higher rates of remission of comorbidities [6-8]. The primary objective of restrictive bariatric surgery is to reduce the intake of calories by anatomical modifications to the upper gastrointestinal tract [9] in addition to inducing positive hormonal and metabolic changes as previously demonstrated [10-12].

The most substantial change in gut hormones occurs in postprandial levels of GLP-1 and PYY, which have been reported to increase significantly [13]. Adding to this, changes in ghrelin secretion have been proposed to contribute to the reduction of food intake [13].

Presently, more than $90 \%$ of bariatric surgical procedures are of the restrictive type, and changes in eating habits are fundamental to ensure prolonged results of the bariatric surgery [14]. In Israel, the most common bariatric surgery is laparoscopic sleeve gastrectomy (LSG) and it is the primary surgery in more than $70 \%$ of patients. It consists of the construction of a narrow tube of stomach, resecting $80 \%$ along the greater curvature.

As a result, there is a decreased appetite due to inhibition of the hormonal appetite pathway. The reasons for the high percentage of this type of surgery are: an acceptable rate of complications, avoidance of a foreign body, maintenance of a normal gastrointestinal continuity, absence of malabsorption, and the possibility of conversion to multiple other operations [15].

Weight gain happens due to a high caloric intake, in relation to energy expenditure. In morbidly obese patients, problems of pathological eating behaviors (EB), causing a high caloric intake, can be found [16]. Eating disorders are a range of psychological disorders characterized by an abnormal or disruptive type of diet.

Eating disorders such as bulimia are characterized by an abnormal pattern of uncontrolled episodic binge eating usually accompanied by self-induced vomiting or laxative abuse to eliminate unwanted food $[17,18]$. Binge eaters are characterized by eating large amounts of food within a limited period of time while experiencing feelings of loss of control; this seems to predict worse outcomes and requires more complex interventions [19]. Night eaters are characterized by hyperphagia manifested by the ingestion of at least $25 \%$ of food their consumption after the evening meal and/or nocturnally; this type of eating pattern can be included in the binge eater group [20].

Preferring sweet tastes presents a risk of obesity, and sweet eaters have an emotional alimentary pattern disorder [21]. Carbohydrate ingestion increases the brain's uptake of tryptophan, the amino acid precursor to serotonin, thereby enhancing brain serotonin 
synthesis and release [21]. On the other hand, ingestion of a sugar-rich diet improves the mood and relieves anxiety. Serotonin plays an important part in regulating pain levels and sleep cycles, and it also has an antidepressant effect [22, 23].

High-calorie snack foods provide a high percentage of the daily calorie intake, especially between meals [24]. Patients after bariatric surgery may prefer this type of eating pattern induced by restriction of the food intake due to surgery.

Eating disorders are a range of psychological disorders characterized by abnormal or disruptive EB. Hence a healthy change in dietary habits is the basis of successful outcomes after bariatric surgeries [25].

Our study has the purpose of comparing the alimentary habits of patients before and after LSG and evaluating the relationship with the operative results. Additionally, associations between weight loss and different demographic and clinical variables, as well as data regarding the level of satisfaction, were studied.

\section{Materials and Methods}

The current study is a single-center prospective midterm follow-up based on patients who underwent LSG from January 2013 through December 2014. In this study, 300 patients were included who underwent LSG as their primary bariatric surgery using the same technique with a bougie of 34 French to calibrate the width of the sleeve.

Patients aged 18 years or older of both genders were included in this study. Patients with complications or difficulty drinking or eating (related to the postoperative course) were excluded. One year after surgery the follow-up was complete in $100 \%$ of the patients, and at the 3-year follow-up 47 patients were lost and the follow-up was completed in 253 (84.3\%) patients. The reasons for the loss to follow-up were: 1 was due to pregnancy, 7 patients changed their telephone number, 15 patients did not answer, and 24 refused the follow-up. Before surgery, the patients were categorized by the bariatric committee, composed of bariatric nutritionists, psychologists, and the bariatric surgeon, into 4 groups according to their eating habits as follows: binge eaters (which includes night eaters), snack eaters, sweet eaters, and overeaters. The follow-up data were actively obtained during outpatient clinic visits or via a telephone questionnaire form (Fig. 1) up to 3 years after the surgery.

Binge eating is a pattern characterized by the existence of episodes of uncontrollable feeding. During such binge eating episodes, a person quickly consumes an excessive amount of food. A diagnosis of binge eating is always associated with feelings of loss of control.

Snack eaters are defined as persons who eat smaller-than-regular portions, generally between meals, several times a day. Sweet eaters are patients with a preference for food rich in sugar, this being the main daily caloric contribution.

The concept of overeaters is less understood; the criterion for classifying a patient as an overeater was the amount of food for each serving that exceeds the daily caloric need. In general, they eat at appropriate time intervals but they need to serve the dishes with food more than once. Unlike binge eaters, overeaters lack compulsion, eat slowly, and feel hunger and satiety.

Healthy eating habits are those who eat regularly at certain times, consciously, without losing control, without frequent snacks, have no preference for sweets, and do not need a large volume of food at each meal.

The patterns of the eating types were determined during a 30- to 40-min interview conducted by each member of the bariatric committee including 2 bariatric nutritionists, which included a questionnaire that evaluated the type, quality, quantity, and time intervals of the patient's eating habits. Based on the interview, and the patient's responses, the bariatric 
Fig. 1. Questionnaire used to follow up eating habits after the surgery.

\section{Eating habits, activities and weight questionnaire}

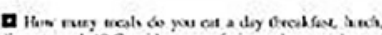

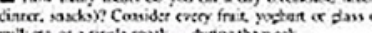

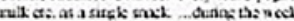

\begin{tabular}{|c|c|}
\hline Quantity wally & $\mathrm{rN}$ \\
\hline $1.2 \pi \times a k$ & \\
\hline 34 mosis & \\
\hline $90 \mathrm{moval} / \mathrm{s}$ & \\
\hline xorads & \\
\hline \multicolumn{2}{|l|}{ At the nechent } \\
\hline Qusintity dutly & VIS \\
\hline 1.2moab & \\
\hline 3.4 axeds & \\
\hline SOSWELK & \\
\hline xines. & \\
\hline
\end{tabular}

- At whishoress do you enolly cat?

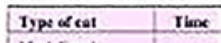

Ued Anask

Wedistios

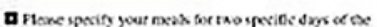

a nowe spering

mixaver

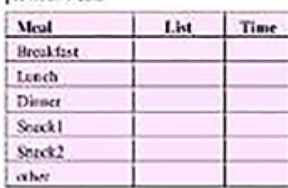

a wzach mes's oo gea wadly eat?

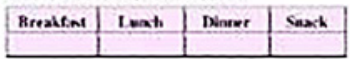

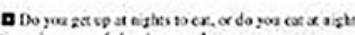

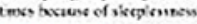
YESTOT

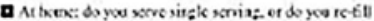

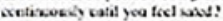

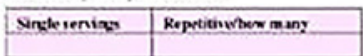

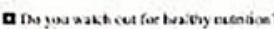

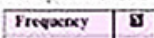

Never

Randy

Ocaviens

Uswits

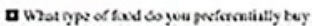

Mesh prepersion to

Presoded ked

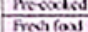

ineren food

Catsed foos

\begin{tabular}{|l|l|}
\hline aher \\
\hline
\end{tabular}

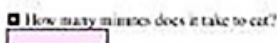

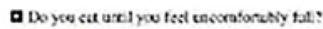

[rimat

a Doyercatale?

yisar

a Doyes ea, resulaty, is troes ef the tisenison:

rimar

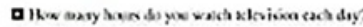

$\square$

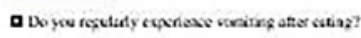

[risnot

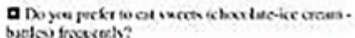

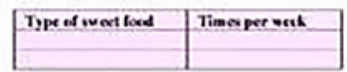

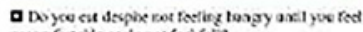
axceifintite ex bo cot fod falt

risnar

a Doyce taste the fones yce ctere ans bie: [rimor Insway ]

a the bo you fed stan you ant

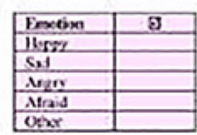

d How axay rave swixt do you dophyvici ativg? $\square$

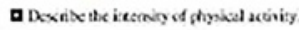

\begin{tabular}{|l|l|}
\hline Ineensity & a \\
\hline Nosovis & \\
\hline
\end{tabular}

Noxove
Macred

Mobrem

brave

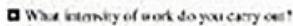

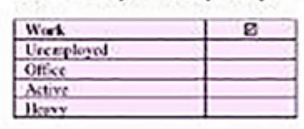

Itiver

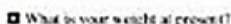

$\mathrm{Ka}$

committee categorized the participants, and thus triangulation and consensus were achieved in order to limit potential bias.

During the 3 years of follow-up, the patients responded periodically to a questionnaire that evaluated changes in eating habits, loss-of-control overeating, emotional eating, vomiting, chewing, spitting out of food, and weight variations.

The change in the body mass index $(\triangle \mathrm{BMI})$ was calculated as the preoperative BMI minus the BMI 3 years after the surgery.

\section{Statistical Analysis}

All of the measured variables and derived parameters were tabulated using descriptive statistics. For categorical variables, the sample size and absolute and relative frequencies are shown. For continuous variables, the sample size, arithmetic mean, SD, median, minimum 
Nikiforova et al.: EB after Gastric Sleeve Gastrectomy

Table 1. Baseline demographics and clinical characteristics of the study participants
Table 2. Distribution of EB before and after surgery

\begin{tabular}{lcc}
\hline Characteristic & Value & Median (range) \\
\hline Demographic and clinical & characteristics & \\
Age, years & $41.65 \pm 11.05$ & $42(18-64)$ \\
Height, m & $1.66 \pm 0.08$ & $2.66(1.55-1.74)$ \\
Weight, kg & $117.83 \pm 17.63$ & $117.38(86-217)$ \\
BMI & $42.02 \pm 5.03$ & $41.5(33-72)$ \\
Males & 33.33 & \\
Females & 66.66 & \\
Comorbidity & & \\
Diabetes & 12 & \\
Hypertension & 21 & \\
Hyperlipidemia & 50 \\
Depression & 9 \\
Severe depression & 8.33 \\
None & 38.66 & \\
Multiple & 18.66 & \\
Metabolic syndrome & 32.66 \\
\hline
\end{tabular}

Values are presented as means \pm SD or percents unless otherwise stated.

\begin{tabular}{lccc}
\hline EB & $\begin{array}{l}\text { Baseline } \\
(n=538)\end{array}$ & $\begin{array}{l}\text { After 3 years } \\
(n=378)\end{array}$ & $p$ value \\
\hline Binge eating & $42(7.8)$ & $42(11.11)$ & 0.08 \\
Snack eating & $150(27.89)$ & $142(37.57)$ & $<0.001^{*}$ \\
Sweet eating & $107(18.89)$ & $122(32.28)$ & $<0.001^{*}$ \\
Overeating & $230(42.75)$ & $7(1.85)$ & $<0.001^{*}$ \\
Healthy & $9(1.67)$ & $65(17.19)$ & $<0.001^{*}$ \\
\hline
\end{tabular}

Values are presented as numbers (\%).* Significant.

and maximum values, and 95\% CI are shown. A t2-sample $t$ test was used to analyze differences in weight loss. An ANOVA test was used to compare weight loss according to different characteristics.

All of the tests were 2-tailed, and a $p \leq 0.05$ was considered statistically significant. The data were analyzed using SAS $^{\circledR}$ version 9.3 (SAS Institute, Cary, NC, USA) and MedCalc ${ }^{\circledR}$ statistical software version 15.3 (Digimizer, Ostend, Belgium).

\section{Results}

\section{Baseline Demographics}

In the 300-patient study population, the ratio of males to females was 1 to 2 , and the average age was $41.65 \pm 11.05$ years. The average baseline BMI was 42.02. The descriptive statistics of the background variables, different characteristics that can influence the operative results, and the related comorbidities are presented in Table 1. A total of 98 (32.7\%) patients with metabolic syndrome were included. 
Nikiforova et al.: EB after Gastric Sleeve Gastrectomy

Table 3. Changes in the number of eating habits before and 3 years after surgery

\begin{tabular}{|c|c|c|c|c|c|}
\hline \multirow[t]{2}{*}{ Eating habit changes } & \multicolumn{2}{|c|}{ Before surgery } & \multicolumn{2}{|c|}{ After 3 years } & \multirow[t]{2}{*}{$p$ value } \\
\hline & $n$ & $\%$ & $n$ & $\%$ & \\
\hline No changes & & & 63 & 24.8 & \\
\hline Change to another eating habit & & & 125 & 49.5 & \\
\hline Healthy eating habits & 9 & 3 & 65 & 25.3 & $<0.0001^{*}$ \\
\hline One type of eating habit & 119 & 39.7 & 77 & 30.4 & $0.0322^{*}$ \\
\hline Two types of eating habits & 118 & 39.3 & 90 & 35.6 & 0.372 \\
\hline Three types of eating habits & 42 & 14 & 18 & 7.1 & $0.0096^{*}$ \\
\hline Four types of eating habits & 12 & 4 & 4 & 1.6 & 0.095 \\
\hline
\end{tabular}

* Significant.

Preoperatively, the main eating habits were identified as follows: binge eating $(n=42$; $7.8 \%)$, snack eating ( $n=150 ; 27.9 \%)$, sweet eating $(n=107 ; 18.9 \%)$, and overeating $(n=$ $230 ; 42.8 \%)$, and $9(1.7 \%)$ patients with healthy eating habits were identified (Table 2). Furthermore, overlap of eating patterns in the same patient was identified frequently, i.e., 119 (39.7\%) patients had 1 type of EB, 118 (39.3\%) had 2 types of EB, $42(14 \%)$ had 3 types of $\mathrm{EB}$, and in 12 (4\%) patients all 4 types of EB were characterized (Table 3 ).

\section{Changes in $E B$}

We examined the eating habits of each patient before surgery and 3 years after the surgery (Table 2). During the follow-up, patients were asked whether they made changes in their eating habits after surgery. Among the responders, 180 (71.8\%) patients believed that they made positive changes in their eating habits after the bariatric surgery. Only 34 patients $(13.5 \%)$ responded that they switched to different habits, especially recognizing that sweet food is their current preference, and 37 patients (14.7\%) denied modifying their diet. When patients were asked to answer questions aimed at elucidating what type of eating habits were preferred and thus classified, significant differences were found between the patient's subjective appreciation and the objective traits evaluated by the professional. Consequently, in response to the questions aimed at elucidating what type of food they ingested at each specific meal, the changes in EB could be elucidated: the number of overeaters was reduced to $7(2.8 \%)$ after surgery $(p<0.001)$. Increases in healthy eating habits were found in 65 $(25.7 \%)$ patients after surgery $(p<0.001)$.

No significant change was found in binge eaters $(p=0.396)$, but the groups of snack eaters and sweet eaters increased, with a 9.0\% increase in the snack eater group $(p<0.001)$ and an increase of $12.94 \%$ in the sweet eater group ( $p<0.001$; Table 2$)$.

Snack eating and sweet eating were the most common forms of EB among morbidly obese patients before surgery, and 3 years after the surgery these unhealthy types of EB got worse, rising from $46.7 \%$ before surgery to $85.3 \%$ after 3 years $(p<0.001)$.

Sixty-five $(24.8 \%)$ patients did not experience changes in their eating patterns. However, after surgery, $24.6 \%$ of the patients continued with the same EB and 125 (49.5\%) patients changed from one EB to another (mostly among the binge and sweet eaters).

The changes in EB that the restrictive surgery caused after 3 years were noteworthy. Of of the original preoperative binge group 13 patients remained binge eaters, but more than $80 \%$ switched to snack-eating and sweet-eating EB. In the preoperative snack-eating group, $50 \%$ did not experience any change 3 years after the surgery; of the other $50 \%$, almost $47 \%$ switched to being binge and sweet eating. 

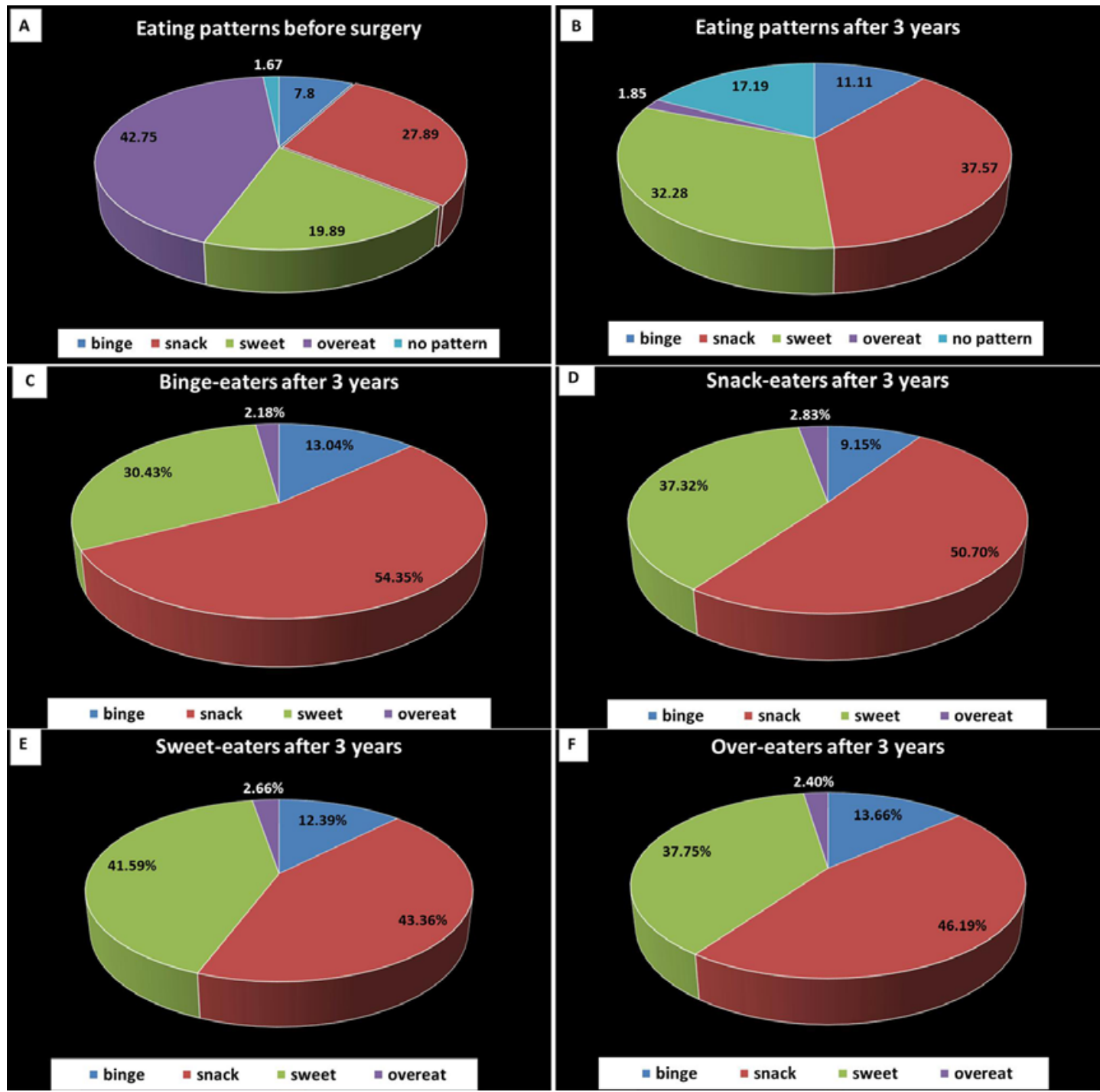

Fig. 2. Distribution of EB. a EB before the surgery. b Distribution of EB 3 years after the surgery. c Distribution of EB 3 years after the surgery in the binge-eating group. $\mathbf{d}$ Distribution of EB 3 years after the surgery in the snack-eating group. e Distribution of EB 3 years after the surgery in the sweet-eating group. $\mathbf{f}$ Distribution of EB 3 years after surgery in the overeating group.

Patients with a single type of EB decreased to $30.4 \%$ after 3 years $(p=0.0322)$. A similar rend occurred in patients with 2, 3, and 4 concomitant types of EB (Table 3). Therefore, it can be stated that LSG reduces the number of unhealthy eating habits. The preoperative EB and those after 3 years are shown in Figure 2.

\section{Loss of Body Weight after Three Years}

The mean BMI was 28.93 after 1 year and 29.84 after 3 years postoperatively, with a $3.1 \%$ weight gain between the first and third years (Fig. 3a). Overall, most of the EB groups lost similar values of body weight, with $\triangle \mathrm{BMI}$ of 12.44 for the binge-eating group, 12.61 for the snack-eating group, 12.15 for the sweet-eating group, and 12.54 for the overeating group, with no significant difference ( $p=0.828$ ), as shown in Figure $3 \mathrm{~b}$. 
Fig. 3. a Weight loss in 3 years. b Weight loss in 3 years according to eating habits .

Fig. 4. Tendency of less weight loss according to healthy eating habits (HEH) and numbers of eating habits. EH, eating habits.
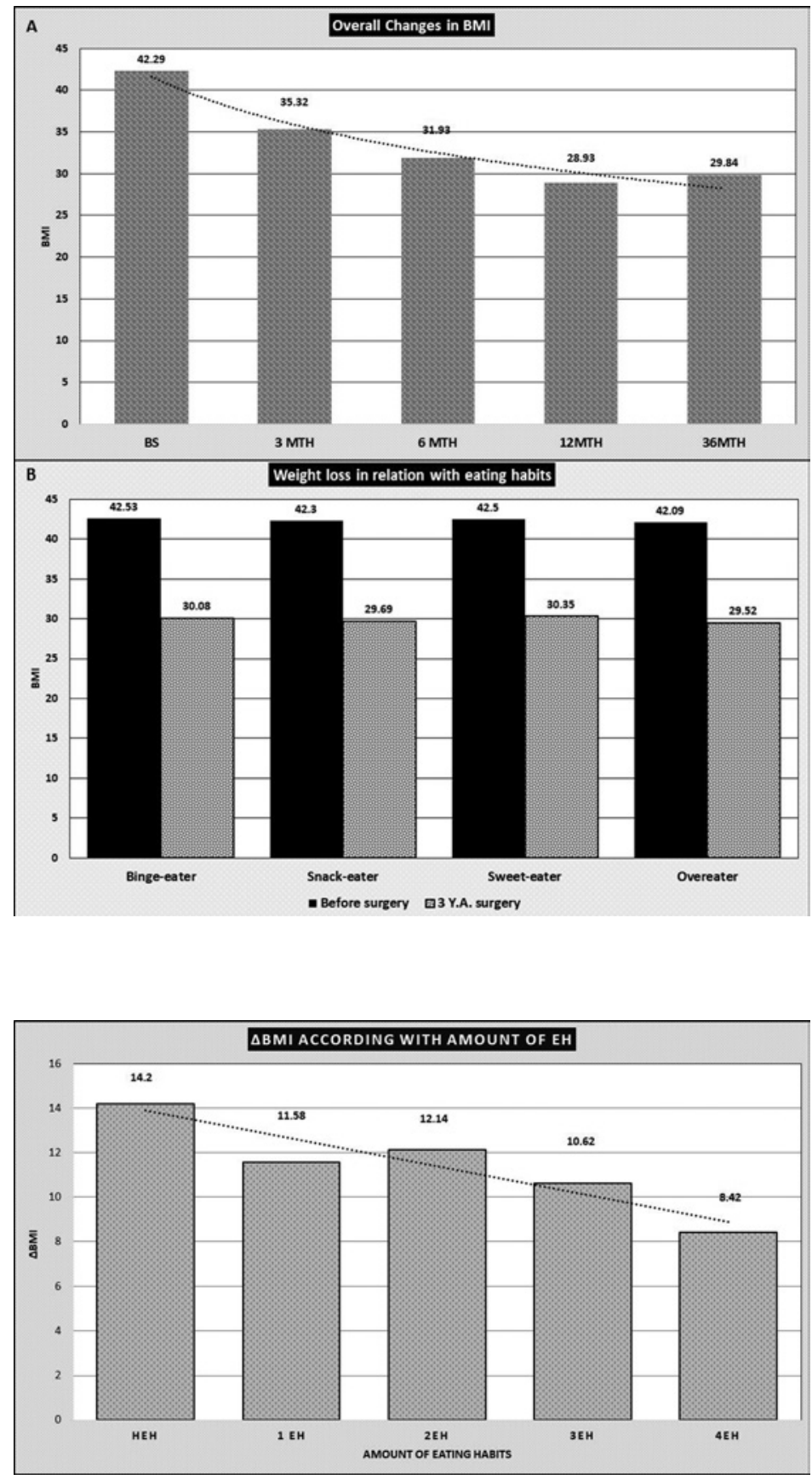

Comparing the weight loss of patients with different amounts of EB, it was found that there was a significant inverse correlation between the numbers of EB presented and weight loss. Those with healthy eating habits had a $\triangle B M I$ of 14.2 , those with $1 \mathrm{~EB}$ had a $\triangle B M I$ of 11.58 , those with $2 \mathrm{~EB}$ had a $\triangle \mathrm{BMI}$ of 12.14 , those with $3 \mathrm{~EB}$ had a $\triangle \mathrm{BMI}$ of 10.6 , and those with $4 \mathrm{~EB}$ had a $\triangle$ BMI of 8.42 ( $p=0.0001$; Fig. 4$)$.

The BMI after 3 years with respect to different characteristics was analyzed. Women lost more weight than men did, but the differences were not significant ( $p=0.065)$. As for age, it was found that patients younger than 30 years significantly lost more weight than patients between 31 and 45 years of age and those older 45 years $(p=0.025)$. Single patients lost more 
Nikiforova et al.: EB after Gastric Sleeve Gastrectomy

Table 4. Weight loss in relation to different characteristics after 3 years

\begin{tabular}{|c|c|c|c|c|}
\hline Characteristic & Variable & BMI & Patients, $n$ & $p$ value \\
\hline \multirow[t]{2}{*}{ Gender } & Male & 30.23 & 87 & \multirow[t]{2}{*}{0.735} \\
\hline & Female & 29.43 & 166 & \\
\hline \multirow[t]{3}{*}{ Age } & Up to 30 years & 28.22 & 42 & \multirow[t]{3}{*}{$0.025^{*}$} \\
\hline & $31-45$ years & 29.68 & 115 & \\
\hline & 46-64 years & 30.35 & 96 & \\
\hline \multirow[t]{3}{*}{ Marital status } & Single & 28.96 & 49 & \multirow[t]{3}{*}{0.193} \\
\hline & Divorced & 29.32 & 21 & \\
\hline & Married & 29.92 & 183 & \\
\hline \multirow[t]{3}{*}{ Physical activity } & None & 30.40 & 84 & \multirow[t]{3}{*}{0.427} \\
\hline & Moderate & 29.07 & 52 & \\
\hline & Intense & 28.69 & 117 & \\
\hline \multirow[t]{4}{*}{ Job } & Unemployed & 30.33 & 13 & \multirow[t]{4}{*}{0.479} \\
\hline & Office work & 29.80 & 183 & \\
\hline & Active work & 29.41 & 31 & \\
\hline & Heavy work & 28.71 & 21 & \\
\hline \multirow[t]{3}{*}{ Smoker } & Yes & 28.28 & 56 & \multirow[t]{3}{*}{0.679} \\
\hline & No & 30.17 & 207 & \\
\hline & No data & & 37 & \\
\hline
\end{tabular}

weight than divorced ones, and both of those groups lost more than married patients did, but the differences were not significant ( $p=0.123$ ).

Engaging in physical activities, either sports or daily workouts, favored weight loss in accordance with the intensity and frequency, but the differences did not show statistical significance ( $p=0.427$ and $p=0.479$, respectively). Smokers lost more weight than nonsmokers did, but here, too, there were no significant differences $(p=0.679)$ as shown in Table 4.

Next, weight loss was analyzed with respect to comorbidities, depression, hyperlipidemia, hypertension, diabetes, and metabolic syndrome, but significant differences in weight loss were not found.

\section{Acceptance and Commitment of Patients Who Underwent LSG}

The patients were also asked if they were satisfied with the results of the LSG, and 91.3\% answered that they were extremely or very satisfied with the results obtained. The patients were asked if the operative results were in accordance with what they expected. Almost $90 \%$ $(89.3 \%)$ answered that the results were what they expected, in terms of improving their quality of life, and $99.7 \%$ responded that their quality of life significantly improved after surgery.

\section{Discussion}

Bariatric surgery has become the most effective treatment for obesity [26], and weight loss is dramatically seen during the course of the first postsurgery year. However, the longterm results of any bariatric procedure must be based on changes in dietary habits [27].

Restrictive bariatric surgery reduces the stomach capacity for caloric intake, which means that changes in eating habits are critical to the success of weight loss and in main- 
taining what has been achieved over an extended period. Yehoshua et al. [28] reported that LSG causes a decrease in volume and an increase in gastric pressure. The volume varies from $1,553 \mathrm{~cm}^{3}$ in an intact stomach to a mean end volume of $129 \mathrm{~cm}^{3}$ after LSG, with a variation in gastric pressure from $34 \mathrm{~mm} \mathrm{Hg}$ in the complete stomach to $43 \mathrm{~mm} \mathrm{Hg}$ in the stomach after LSG [28]. Hence, Monteleone et al. [29] affirm that bariatric patients need to either engage in the process of making life modifications or suffer from complications.

Alvarez et al. [30] concluded that the weight regain after LSG is due to the loss of the procedure's restrictive effect. In our group of patients, it is noteworthy that the restrictive effect of LSG greatly reduces the number of overeaters, which can be explained first by the decrease in gastric capacity and second by the decrease in appetite as a consequence of metabolic changes induced by the operation. In our cohort of patients, there was a $97.4 \%$ reduction in overeaters mainly because of the impossibility of eating a large volume of food after the LSG surgery, though we have not noticed a loss of restriction after 3 years.

Bad eating habits, particularly binge eating, are fairly common among obese patients, with expected poor outcomes found in $10-15 \%$ of obese patients [31]. Lent et al. [32] demonstrated that food addiction does not influence weight loss after bariatric surgery, coinciding with our results. Contrary, Burmeister et al. [33] found that a bad eating habit symptomatology correlated with poorer weight loss. However, the results of this study demonstrate that weight loss is satisfactory and similar for all groups. Therefore, our results do not support selecting patients based on their eating habits before the operation.

Patients with anomalous eating habits may benefit from more intensive preoperative nutritional and psychosocial counseling as Chao et al. [34] recommend. In this way, patients who present for bariatric surgery are better prepared, with a good understanding of the psychosocial and dietary changes they will face in the postoperative period; therefore, the long-term results could be better [35].

It is very interesting that $25 \%$ of our patients did not experience changes in their EB but almost $50 \%$ changed from one type of EB to another type of pathological feeding. More than $90 \%$ became snack, binge and sweet eaters, which did not significantly affect their weight loss results. In the sweet-eating group, the switch to different eating types was similar to that of the snack-eating group and in the preoperative overeating group more than $80 \%$ switched to snack eating and sweet eating. Presumably, the restriction caused by LSG probably promotes the increase in snack eaters and sweet eaters in the face of the reduction in the capacity for bulky intake and thus the feeling of satisfaction. We agree with a recent article focused on eating patterns after bariatric surgery and the risks of exacerbating eating disorders [36], but more studies about the worsening of alimentary habits and especially the overlap of eating patterns are necessary to better understand our finding.

We also found that in all types of EB there were important changes in eating habits that were not exactly healthy, i.e., changes from overeating to sweet or snack eating more commonly. We agree with Macht [37] in that changes in diet can be the result of the interference of food through emotions, where emotions can regulate food and vice versa.

Furthermore, $3 \%$ of the patients did not have recognizable pathological eating habits before the operation, and 3 years later $25 \%$ had healthy eating habits. However, the remaining $75 \%$ of the patients are candidates for weight gain in the long-term due to continued long term bad EB [38]. Behavioral modifications might not be the answer since patients undergoing behavioral treatment for EB have a demonstrated resistance to changing their eating patterns [39]. In our patients, we found positive changes in eating habits in $22 \%$ of cases, which leads us to believe that an intensive behavioral treatment may impair the resistance to achieving healthy changes in alimentary habits [40].

The change from one EB to another unhealthy eating habit may ultimately negatively affect the results of the bariatric surgery. We did not find in the literature a description of 
Nikiforova et al.: EB after Gastric Sleeve Gastrectomy

our findings regarding changes in eating habits caused by bariatric surgery. Moreover, unsatisfactory treatment of unhealthy EB, with a low percentage of success, has been reported $[41,42]$.

Treatment for EB must include a wide range of objectives such as emotional support with medications, changes in motivation, and environmental modifications [43].

Sawamoto [44] reported that interventions to change health behaviors have had limited success to date at establishing enduring healthy lifestyle habits, with a $68.6 \%$ unsuccessful rate.

Since not all EB are currently treatable, some have proposed having a healthier food supply by intervening in the production of food, improving its composition, and reducing the amount high-calorie food components, especially sweet, fatty, and salty foods, to improve the taste and thus facilitate its marketing $[45,46]$. In our country, the health ministry has implemented laws that require food producers to mark packagings to aid in recognition of unhealthy or high-calorie foods, which could help to improve eating habits.

We also analyzed our results in relation to different variables. In terms of gender, we did not find significant differences, but age did show weight loss differences. We found that patients older than 45 years lost significantly less weight than younger patients did, which is similar to the results of Giordano and Victorzon [47]. This age difference can be explained by a decrease in basic body metabolism [48], less physical activity, and less exercise intensity. Current research suggests that the addition of an exercise program to dietary restriction can promote more favorable changes in body composition than diet or physical activity alone [49]. It has been found that the combination of cognitive-behavioral methods and exercise for improved eating improves weight loss through effects on the psychosocial factors of selfregulation, self-efficacy, and overall mood more than standard nutrition education alone [50].

In our cohort of patients, we found no significant differences in terms of weight loss due to marital status but there was a slight tendency of married patients to experience a lesser weight loss, similar to what was expressed by Nguyen et al. [51].

The data on the occupational activities of patients suffering from obesity is limited. In our study group, we found that more than $60 \%$ perform office work and $20 \%$ perform work involving physical activity. Capodaglio et al. [52] reviewed the physiological and biomechanical causes of the reduced work capacity in obese workers caused by a reduced spine flexibility, a decline in endurance, a limited range of movement of the major joints, reduced muscle strength and capacity to hold fixed postures for prolonged periods, and impaired respiratory capacity and visual control. We did not see any influence of occupational differences in our group of patients on the LSG results. However, we saw the importance of physical activity to ensure optimal results after bariatric procedures. Our study together with other studies shows that BMI is inversely related to the total amount and intensity of physical activity $[53,54]$.

Data analysis showed that patients who smoked had a more significant weight loss in relation to those who did not smoke. Smoking is associated with a decreased food intake and a lower body weight [55]. However, the combination of obesity with smoking increases the risk of premature death more than ten-fold and the risk of obesity increases with the number of cigarettes per day [56].

This research provides data demonstrating that selection of patients for bariatric surgery according to their EB is not necessary and does not influence the results of LS; this also applies to patients with an overlap of EB, which is very frequent. We also found that, despite a satisfactory weight loss, 3 years after LSG patients do not show improvement of their EB - on the contrary, they worsen; Chao et al. [34] found that the presence of poor preoperative EB leads to unsatisfactory weight loss after bariatric surgery but, as the author expresses, food addiction it is a controversial concept and therefore our study is based on clearly specified EB. 
We noted a high rate of satisfaction and an improved quality of life in our patients after LSG, similar to what has been found in previous publications $[57,58]$; these factors can positively affect motivation and decreased anxiety which could help provoke changes in EB along with professional support.

Worsening of dietary habits may be the cause of the long-term weight gain seen after LSG. Felsenreich et al. [59] reported a rate of $59 \%$ of patients who regain weight 10 years after LSG. Long-term studies are needed to determine changes in eating habits after LSG and their influence on the final results. Proposed causes of weight regain include the initial sleeve size, sleeve dilation, increased ghrelin levels, inadequate follow-up support, and maladaptive lifestyle behaviors [60]. The results of this study support the conclusion that patients who undergo bariatric surgery should be followed by a multidisciplinary team to promote lifestyle changes in a prolonged manner [26].

Further studies with prolonged follow-ups are necessary to corroborate our results more faithfully; this type of study presents the limitation of classifying patients according to their eating habits, which is a complex task with subjective components.

\section{Conclusions}

EB are hard to modify but, as expected, restrictive surgery promoted the reduction of overeaters. However, LSG also promoted a switch between different eating patterns but did not affect weight loss at 3 postoperative years. The number of snacks and sweet eaters increased after LSG. Worsening of eating habits after LSG is a frequent occurrence after restrictive bariatric surgery.

\section{Statement of Ethics}

This study was approved by the institution's ethics committee (Helsinki board), and the trial was registered on the National Institutes of Health website (ClinicalTrials.gov; identifier NCT02733562).

\section{Disclosure Statement}

The authors declare no conflict of interests.

\section{Funding Sources}

There were no sources of support for this study.

\section{Author Contributions}

We confirm that the final version of this paper was read and approved by all of the authors. 
Nikiforova et al.: EB after Gastric Sleeve Gastrectomy

\section{References}

1 Kitzinger HB, Karle B. The epidemiology of obesity. Eur Surg. 2013;2(2):80-2.

2 Secord AA, Gehrig PA. Obesity: too big a problem to ignore. Gynecol Oncol. 2012 Aug;126(2):274-6.

3 Saikia D, Ahmed SJ, Saikia H, Sarma R. Overweight and obesity in early adolescents and its relation to dietary habit and physical activity: a study in Dibrugarh town. Clin Epidemiol Glob Health. 2016;4:22-8.

4 Hill JO, Wyatt HR, Reed GW, Peters JC. Obesity and the environment: where do we go from here? Science. 2003 Feb;299(5608):853-5.

5 Yanovski SZ, Yanovski JA. Long-term drug treatment for obesity: a systematic and clinical review. JAMA. 2014 Jan;311(1):74-86.

6 Mingrone G, Panunzi S, De Gaetano A, Guidone C, Iaconelli A, Nanni G, et al. Bariatric-metabolic surgery versus conventional medical treatment in obese patients with type 2 diabetes: 5 year follow-up of an open-label, single-centre, randomised controlled trial. Lancet. 2015 Sep;386(9997):964-73.

7 Gloy VL, Briel M, Bhatt DL, Kashyap SR, Schauer PR, Mingrone G, et al. Bariatric surgery versus non-surgical treatment for obesity: a systematic review and meta-analysis of randomised controlled trials. BMJ. 2013 Oct; 347:5934.

8 Kushner RF. Weight loss strategies for treatment of obesity. Prog Cardiovasc Dis. 2014 Jan-Feb;56(4):465-72.

9 DeMaria EJ. Bariatric surgery for morbid obesity. N Engl J Med. 2007 May;356(21):2176-83.

10 Adams TD, Davidson LE, Litwin SE, Kim J, Kolotkin RL, Nanjee MN, et al. Weight and metabolic outcomes 12 years after gastric bypass. N Engl J Med. 2017 Sep;377(12):1143-55.

11 Wolfe BM, Schoeller DA, McCrady-Spitzer SK, Thomas DM, Sorenson CE, Levine JA. Resting Metabolic Rate, Total Daily Energy Expenditure, and Metabolic Adaptation 6 Months and 24 Months After Bariatric Surgery. Obesity (Silver Spring). 2018 May;26(5):862-8.

12 Alamuddin N, Vetter ML, Ahima RS, Hesson L, Ritter S, Minnick A, et al. Changes in Fasting and Prandial Gut and Adiposity Hormones Following Vertical Sleeve Gastrectomy or Roux-en-Y-Gastric Bypass: an 18-Month Prospective Study. Obes Surg. 2017 Jun;27(6):1563-72.

13 Stefanidis A, Oldfield BJ. Neuroendocrine mechanisms underlying bariatric surgery: insights from human studies and animal models. J Neuroendocrinol. 2017 Oct;29(10):e12534.

14 Angrisani L, Santonicola A, Iovino P, Formisano G, Buchwald H, Scopinaro N. Bariatric Surgery Worldwide 2013. Obes Surg. 2015 Oct;25(10):1822-32.

15 Gumbs AA, Gagner M, Dakin G, Pomp A. Sleeve gastrectomy for morbid obesity. Obes Surg. 2007 Jul;17(7): 962-9.

16 Brownell KD, Walsh BT, editors. Eating disorders and obesity: A comprehensive handbook. 3rd ed. New York, New York: The Guilford Press; 2017.

17 Dimitriadis E, Daskalakis M, Kampa M, Peppe A, Papadakis JA, Melissas J. Alterations in gut hormones after laparoscopic sleeve gastrectomy: a prospective clinical and laboratory investigational study. Ann Surg. 2013 Apr;257(4):647-54.

18 Palou A, Serra F, Bonet ML, Picó C. Obesity: molecular bases of a multifactorial problem. Eur J Nutr. 2000 Aug; 39(4):127-44.

19 Pyle RL, Mitchell JE. The prevalence of bulimia in selected samples. Adolesc Psychiatry. 1986;13:241-52.

20 Conceição EM, Utzinger LM, Pisetsky EM. Eating Disorders and Problematic Eating Behaviours Before and After Bariatric Surgery: Characterization, Assessment and Association with Treatment Outcomes. Eur Eat Disord Rev. 2015 Nov;23(6):417-25.

21 Kate PE, Deshmukh GP, Datir RP, Rao JK. Good mood foods. J Nutr Health Food Eng. 2017; 7(4):246.

22 Pull CB. Binge eating disorder. Curr Opin Psychiatry. 2004;17(1):43-8.

23 Robinson AH, Safer DL. Moderators of dialectical behavior therapy for binge eating disorder: results from a randomized controlled trial. Int J Eat Disord. 2012 May; 45(4):597-602.

24 Allison DB, Heshka S. Emotion and eating in obesity? A critical analysis. Int J Eat Disord. 1993 Apr;13(3):289_ 95.

25 Figura A, Ahnis A, Stengel A, Hofmann T, Elbelt U, Ordemann J, et al. Determinants of weight loss following laparoscopic sleeve gastrectomy: the role of psychological burden, coping style, and motivation to undergo surgery. . J Obes. 2015;2015:626010.

26 Karmali S, Johnson Stoklossa C, Sharma A, Stadnyk J, Christiansen S, Cottreau D, Birch DW. Bariatric surgery: a primer. Can Fam Physician. 2010 Sep;56(9):873-9.

27 Cornejo MP, Hentges ST, Maliqueo M, Coirini H, Becu-Villalobos D, Elias CF. Neuroendocrine Regulation of Metabolism. J Neuroendocrinol. 2016 Jul;28(7): https://doi.org/10.1111/jne.12395.

28 Yehoshua RT, Eidelman LA, Stein M, Fichman S, Mazor A, Chen J, et al. Laparoscopic sleeve gastrectomy: volume and pressure assessment. Obes Surg. 2008;18(9):1083-8.

29 Monteleone P, Castaldo E, Maj M. Neuroendocrine dysregulation of food intake in eating disorders. Regul Pept. 2008;149(1):39-50.

30 Alvarez V, Carrasco F, Cuevas A, Valenzuela B, Muñoz G, Ghiardo D, et al. Mechanisms of long-term weight regain in patients undergoing sleeve gastrectomy. Nutrition. 2016 Mar;32(3):303-8.

31 Duarte-Guerra LS, Coêlho BM, Santo MA, Lotufo-Neto F, Wang YP. Morbidity persistence and comorbidity of mood, anxiety, and eating disorders among preoperative bariatric patients. Psychiatry Res. 2017 Nov; 257: $1-6$. 
Nikiforova et al.: EB after Gastric Sleeve Gastrectomy

32 Lent MR, Eichen DM, Goldbacher E, Wadden TA, Foster GD. Relationship of food addiction to weight loss and attrition during obesity treatment. Obesity (Silver Spring). 2014 Jan;22(1):52-5.

33 Burmeister JM, Hinman N, Koball A, Hoffmann DA, Carels RA. Food addiction in adults seeking weight loss treatment. Implications for psychosocial health and weight loss. Appetite. 2013 Jan;60(1):103-10.

34 Chao AM, Wadden TA, Faulconbridge LF, Sarwer DB, Webb VL, Shaw JA, et al. Binge-eating disorder and the outcome of bariatric surgery in a prospective, observational study: two-year results. Obesity (Silver Spring). 2016 Nov;24(11):2327-33.

35 Conceição E, Vaz A, Bastos AP, Ramos A, Machado P. The development of eating disorders after bariatric surgery. Eat Disord. 2013;21(3):275-82.

36 Lautenbach A, Kulinna U, Löwe B, Rose M. $100 \mathrm{~kg}$ more or less, still the same person (and disorder): from overweight to underweight-exacerbation of an eating disorder after bariatric surgery. Int J Eat Disord. 2013 Apr;46(3):280-3.

37 Macht M. How emotions affect eating: a five-way model. Appetite. 2008 Jan;50(1):1-11.

38 Hsu LK, Benotti PN, Dwyer J, Roberts SB, Saltzman E, Shikora S, et al. Nonsurgical factors that influence the outcome of bariatric surgery: a review. Psychosom Med. 1998 May-Jun;60(3):338-46.

39 Sarwer DB, Wadden TA, Fabricatore AN. Psychosocial and behavioral aspects of bariatric surgery. Obes Res. 2005 Apr;13(4):639-48.

40 Hsu LK, Betancourt S, Sullivan SP. Eating disturbances before and after vertical banded gastroplasty: a pilot study. Int J Eat Disord. 1996 Jan;19(1):23-34.

41 Craighead LW, Smith L. Obesity and eating disorders: handbook of assessment and treatment planning for psychological disorders. 2nd ed. New York: Guilford; 2002. p. 300-40.

42 Masheb RM, Grilo CM. Eating patterns and breakfast consumption in obese patients with binge eating disorder. Behav Res Ther. 2006 Nov;44(11):1545-53.

43 Popovic-Lipovac A, Strasser B. A review on changes in food habits among immigrant women and implications for health. J Immigr Minor Health. 2015 Apr;17(2):582-90.

44 Sawamoto R, Nozaki T, Nishihara T, Furukawa T, Hata T, Komaki G, et al. Predictors of successful long-term weight loss maintenance: a two-year follow-up. Biopsychosoc Med. 2017 Jun;11(1):14.

45 Hawkes C, Smith TG, Jewell J, Wardle J, Hammond RA, Friel S, et al. Smart food policies for obesity prevention. Lancet. 2015 Jun;385(9985):2410-21.

46 Swinburn BA. Obesity prevention: the role of policies, laws and regulations. Aust New Zealand Health Policy. 2008 Jun;5(1): 12

47 Giordano S, Victorzon M. Laparoscopic Roux-En-Y Gastric Bypass in Elderly Patients (60 Years or Older): A Meta-Analysis of Comparative Studies. Scand J Surg. 2018 Mar;107(1):6-13.

48 Asp M, Simonsson B, Larm P, Molarius A. Physical mobility, physical activity, and obesity among elderly: findings from a large population-based Swedish survey. Public Health. 2017 Jun;147:84-91.

49 Stiegler P, Cunliffe A. The role of diet and exercise for the maintenance of fat-free mass and resting metabolic rate during weight loss. Sports Med. 2006;36(3):239-62.

50 Annesi J. Effects of treatment differences on psychosocial predictors of exercise and improved eating in obese, middle-age adults. J Phys Act Health. 2013 Sep;10(7):1024-31.

51 Nguyen NT, Kim E, Vu S, Phelan M. Ten-year Outcomes of a Prospective Randomized Trial of Laparoscopic Gastric Bypass Versus Laparoscopic Gastric Banding. Ann Surg. 2018 Jul;268(1):106-13.

52 Capodaglio P, Castelnuovo G, Brunani A, Vismara L, Villa V, Capodaglio EM. Functional limitations and occupational issues in obesity: a review. Int J Occup Saf Ergon. 2010;16(4):507-23.

53 King WC, Belle SH, Eid GM, Dakin GF, Inabnet WB, Mitchell JE, et al.; Longitudinal Assessment of Bariatric Surgery Study. Physical activity levels of patients undergoing bariatric surgery in the Longitudinal Assessment of Bariatric Surgery study. Surg Obes Relat Dis. 2008 Nov-Dec;4(6):721-8.

54 Cárdenas Fuentes G, Bawaked RA, Martínez González MÁ, Corella D, Subirana Cachinero I, Salas-Salvadó J, et al. Association of physical activity with body mass index, waist circumference and incidence of obesity in older adults. Eur J Public Health. 2018 Oct;28(5):944-50.

55 Jo YH, Talmage DA, Role LW. Nicotinic receptor-mediated effects on appetite and food intake. J Neurobiol. 2002 Dec;53(4):618-32.

56 Chen H, Vlahos R, Bozinovski S, Jones J, Anderson GP, Morris MJ. Effect of short-term cigarette smoke exposure on body weight, appetite and brain neuropeptide Y in mice. Neuropsychopharmacology. 2005 Apr;30(4): 713-9.

57 Kafri N, Valfer R, Nativ O, Shiloni E, Hazzan D. Health behavior, food tolerance, and satisfaction after laparoscopic sleeve gastrectomy. Surg Obes Relat Dis. 2011 Jan-Feb;7(1):82-8.

58 D'Hondt M, Vanneste S, Pottel H, Devriendt D, Van Rooy F, Vansteenkiste F. Laparoscopic sleeve gastrectomy as a single-stage procedure for the treatment of morbid obesity and the resulting quality of life, resolution of comorbidities, food tolerance, and 6-year weight loss. Surg Endosc. 2011 Aug;25(8):2498-504.

59 Felsenreich DM, Langer FB, Kefurt R, Panhofer P, Schermann M, Beckerhinn P, et al. Weight loss, weight regain, and conversions to Roux-en-Y gastric bypass: 10-year results of laparoscopic sleeve gastrectomy. Surg Obes Relat Dis. 2016 Nov;12(9):1655-62.

60 Lauti M, Kularatna M, Hill AG, MacCormick AD. Weight Regain Following Sleeve Gastrectomy-a Systematic Review. Obes Surg. 2016 Jun;26(6):1326-34. 